\title{
FREE VIBRATION OF A CANTILEVER TAPERED TIMOSHENKO BEAM
}

\author{
Dawid Cekus \\ Institute of Mechanics and Machine Design Foundations \\ Czestochowa University of Technology, Czestochowa, Poland \\ cekus@imipkm.pcz.pl
}

\begin{abstract}
In this paper the Lagrange multiplier formalism has been used to find a solution of free vibration problem of a cantilever tapered beam. The beam has been circumscribed according to the Timoshenko theory. The sample numerical calculations for the cantilever tapered beam have been carried out and compared with experimental results to illustrate the correctness of the present method.
\end{abstract}

\section{Introduction}

Beams, whose geometry and/or material properties vary along the length, have practical importance in engineering design, for instance they are used to reduce weight or volume as well as to increase strength and stability of structures. Therefore, non-uniform beams have been the subject of research of many authors. The typically non-uniform beams have been circumscribed according to the Bernoulli-Euler [1-3] or Timoshenko [3-8] theory. The Timoshenko theory [9, 10] is adequate for vibrations of higher modes or for short beams.

In this paper, the free vibration problem of the cantilever tapered beam has been formulated and solved with the help of the Lagrange multiplier formalism [11, 12]. The beam has been circumscribed according to the Timoshenko theory. Exemplary numerical calculations have been carried out and compared with the experimental results.

\section{Formulation and solution of the problem}

Considering the vibrations of the cantilever tapered beam, the beam can approximate to a system of $N$ segments (Fig. 1).

Each segment is described according to the Timoshenko theory and has constant parameters: $\rho$ - the mass density, $A(x)$ - the cross-sectional area, $I(x)$ - the area moment of inertia, $E$ - the modulus of elasticity, $G$ - the shear modulus and $k^{\prime}$ a numerical factor depending on the shape of the cross-section. 

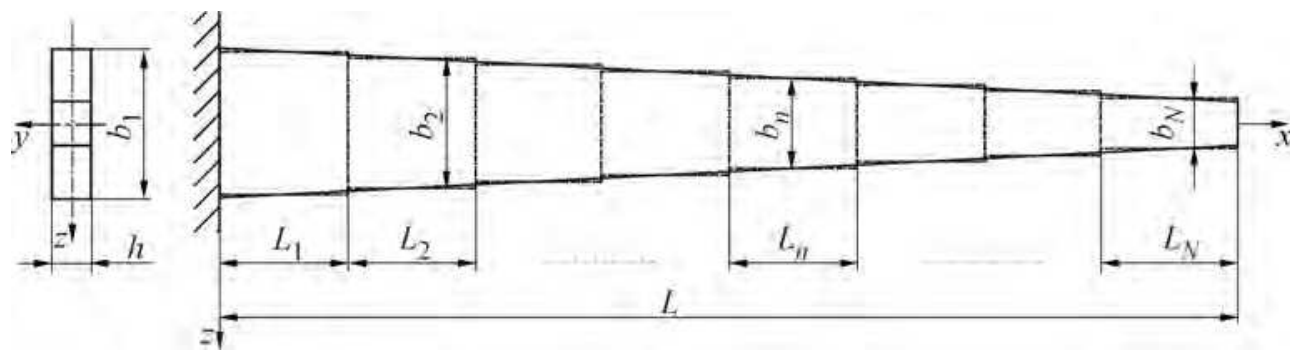

Fig. 1. An approximation of the cantilever tapered beam by stepped beams

Acting on the Lagrange multiplier formalism [11-13], the free vibration problem of the analyzed system has been formulated and the solution has been reduced to the matrix system of equations in the following form:

$$
\mathbf{C \Lambda}=0,
$$

where:

$$
\boldsymbol{\Lambda}=\left[\Lambda_{1}, \Lambda_{2}, \ldots, \Lambda_{2 N}\right]^{T}
$$

is the vector of Lagrange multipliers and band matrix $\mathbf{C}$ has the form:

$$
\mathbf{C}=\left[\begin{array}{ccccccccc}
\mathbf{C}_{1,1} & \mathbf{C}_{1,2} & 0 & 0 & 0 & \ldots & 0 & 0 & 0 \\
\mathbf{C}_{2,1} & \mathbf{C}_{2,2} & \mathbf{C}_{2,3} & 0 & 0 & \ldots & 0 & 0 & 0 \\
0 & \mathbf{C}_{n, n-1} & \mathbf{C}_{n, n} & \mathbf{C}_{n, n+1} & 0 & \ldots & 0 & 0 & 0 \\
0 & 0 & \mathbf{C}_{n+1, n} & \mathbf{C}_{n+1, n+1} & \mathbf{C}_{n+1, n+2} & \ldots & 0 & 0 & 0 \\
0 & 0 & 0 & \mathbf{C}_{n+2, n+1} & \mathbf{C}_{n+2, n+2} & \ldots & 0 & 0 & 0 \\
\ldots & \ldots & \ldots & \ldots & \ldots & \ldots & \ldots & \ldots & \ldots \\
0 & 0 & 0 & 0 & 0 & \ldots & \mathbf{C}_{N-2, N-2} & \mathbf{C}_{N-2, N-1} & 0 \\
0 & 0 & 0 & 0 & 0 & \ldots & \mathbf{C}_{N-1, N-2} & \mathbf{C}_{N-1, N-1} & \mathbf{C}_{N-1, N} \\
0 & 0 & 0 & 0 & 0 & \ldots & 0 & \mathbf{C}_{N, N-1} & \mathbf{C}_{N, N}
\end{array}\right]
$$

The sub-matrices on the diagonal have the form:

$$
\begin{gathered}
\mathbf{C}_{1,1}=\left[\begin{array}{ll}
C_{1_{1,1}} & C_{1_{1,2}} \\
C_{1_{2,1}} & C_{1_{2,2}}
\end{array}\right], \\
\mathbf{C}_{n, n}=\left[\begin{array}{cc}
C_{n-1_{2 n-1,2 n-1}}+C_{n_{2 n-1,2 n-1}} & C_{n-1_{2 n-1,2 n}}+C_{n_{2 n-1,2 n}} \\
C_{n-1_{2 n, 2 n-1}}+C_{n_{2 n, 2 n}-1} & C_{n-1_{2 n, 2 n}}+C_{n_{2 n, 2 n}}
\end{array}\right],
\end{gathered}
$$


and the sub-matrices above and below the diagonal have the form:

$$
\begin{gathered}
\mathbf{C}_{1,2}=\mathbf{C}_{2,1}^{T}=\left[\begin{array}{ll}
C_{1_{1,3}} & C_{1_{1,4}} \\
C_{1_{2,3}} & C_{1_{2,4}}
\end{array}\right], \\
\mathbf{C}_{n, n+1}=\mathbf{C}_{n+1, n}^{T}=\left[\begin{array}{cc}
-C_{n_{2 n-1,2 n+1}} & -C_{n_{2 n-1,2(n+1)}} \\
-C_{n_{2 n, 2 n+1}} & -C_{n_{2 n, 2(n+1)}}
\end{array}\right] .
\end{gathered}
$$

Coefficients $C_{n k, r}$ have been defined as:

$$
C_{n_{k, r}}=\sum_{i=0}^{m} \frac{b_{n_{i, k}} b_{n_{i, r}}}{K_{n_{i}}-\omega^{2} M_{n_{i}}}
$$

and they characterize the dynamic properties of separate segments of the beam. The introduced denotations $b_{n i, r}$ represent the $i$-th translational and rotational vibrational modes of $n$-th beam segments without additional elements:

$$
b_{n_{i, r}}=\left\{\begin{array}{l}
Y_{n_{i}}\left(x_{n, r}\right) \text { for } r=1,3,5, \ldots, 2 N-1, n=1,2, \ldots, N \\
\Psi_{n_{i}}\left(x_{n, r}\right) \text { for } r=2,4,6, \ldots, 2 N, n=1,2, \ldots, N
\end{array}\right.
$$

where:

$$
x_{n, r}=\left\{\begin{array}{c}
0 \text { for } r=\left\{\begin{array}{c}
2 n-1 \\
2 n
\end{array}\right. \\
L_{n} \text { for } r=\left\{\begin{array}{l}
2 n+1 \\
2 n+2
\end{array}\right.
\end{array} .\right.
$$

A more detailed explanation and complement of the above-mentioned mathematical expressions are placed in works [11-13].

From the condition of existing of nontrivial solution of system of equations (1), the equation of free vibration frequencies $\left(\omega_{i}\right)$ of the beam has been obtained in the form of

$$
\operatorname{det} \mathbf{C}=0
$$

\section{Numerical and experimental research}

On the basis of presented mathematical model, the algorithm and computer program have been worked out and numerical calculations have been carried out. 
In order to check the reliability and accuracy of present method (numerical results) the experimental research have been performed.

A numerical calculations have been worked out for the cantilever tapered beam (Fig. 1) made of steel St3S with the parameters: thickness $h=5 \mathrm{~mm}$, length $L=500 \mathrm{~mm}$, width: $b_{1}=75 \mathrm{~mm}$ and $b_{N}=20 \mathrm{~mm}$. The shear coefficient has been assumed on the basis of work [14]:

$$
k^{\prime}=\frac{10(1+v)}{12+11 v},
$$

where $v$ is the Poisson's ratio, and in the analyzed cases it is equal 0.3 .

In Table 1, the first five natural frequencies obtained by taking into account ten and twenty segments approximating to the tapered beam, and also fifteen and thirty terms of coefficients $C_{n_{k, r}}(6)$, have been shown.

Table 1

Frequencies from the numerical calculations of the cantilever tapered beam

\begin{tabular}{|c|c|c|c|c|c|c|}
\hline \multirow{2}{*}{$\begin{array}{c}\text { Number of } \\
\text { segments }\end{array}$} & \multirow{2}{*}{$\begin{array}{c}\text { Number of terms of } \\
\text { coefficients } C_{n_{k, r}}\end{array}$} & \multicolumn{6}{|c|}{ Frequencies [Hz] } \\
\cline { 3 - 7 }$N=10$ & $m=15$ & 24.996 & 121.218 & 313.247 & 599.011 & 979.615 \\
\cline { 2 - 7 } & $m=30$ & 24.343 & 117.982 & 304.626 & 581.908 & 950.51 \\
\hline \multirow{2}{*}{$N=20$} & $m=15$ & 24.327 & 118.912 & 308.05 & 589.212 & 963.056 \\
\cline { 2 - 7 } & $m=30$ & 23.405 & 114.415 & 296.36 & 566.706 & 925.972 \\
\hline
\end{tabular}

The measurement system which has been used to the experimental investigations is presented in Figure 2. This system consists of the fixed beam (1), PC computer (2) with appropriate software, four-channel vibration analyzer (3), hammer (4) and one-axial piezoelectric accelerometer (5).

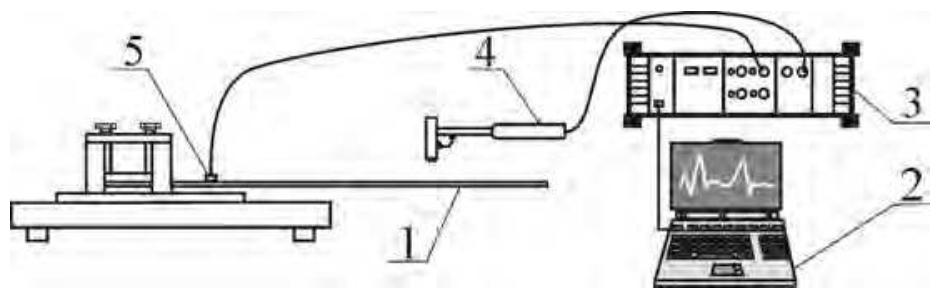

Fig. 2. Scheme of the measuring set

The modal model (set of natural frequencies and modes of vibrations) of the system has been obtained as a result of the experimental research.

In Figures 3 and 4 the first five received natural frequencies and corresponding modes of vibrations are shown. 


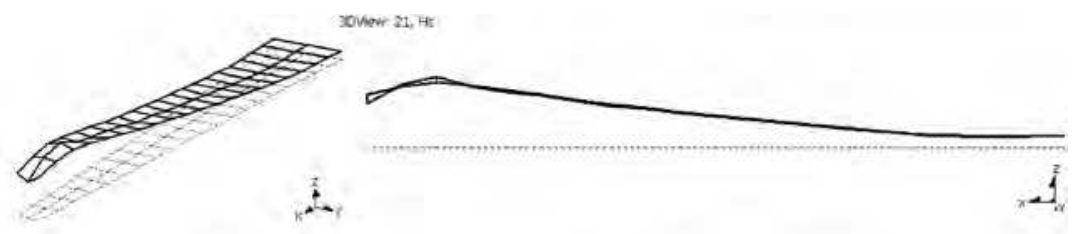

Fig. 3. The experimental first free vibration frequency and the mode (isometric and right view) of the beam

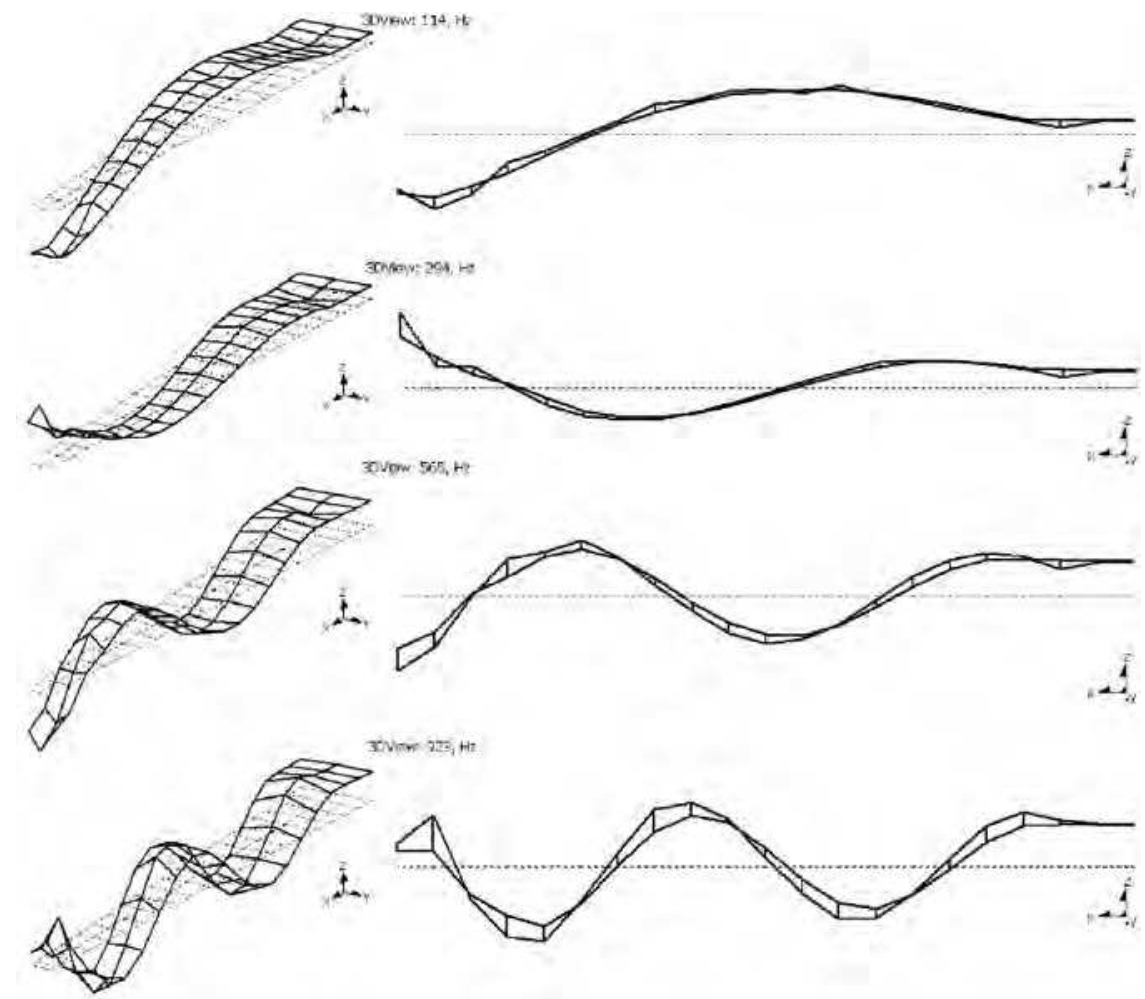

Fig. 4. The experimental free vibration frequencies (2-4) and the modes (isometric and right views) of the beam

In Table 2, the best numerical results are collated with the experimental results, and the relative error between them is illustrated.

Table 2

Comparison of numerical and experimental results and the relative error between them

\begin{tabular}{|c|c|c|c|c|c|}
\hline & \multicolumn{5}{|c|}{ Frequencies [Hz] } \\
\cline { 2 - 6 } & $\omega_{1}$ & $\omega_{2}$ & $\omega_{3}$ & $\omega_{4}$ & $\omega_{5}$ \\
\hline Numerical results $\left(\omega_{t}\right)$ & 23.405 & 114.415 & 296.36 & 566.706 & 925.972 \\
\hline Experimental results $\left(\omega_{e}\right)$ & 21 & 114 & 294 & 565 & 923 \\
\hline$\Delta \omega_{i}=\left|\frac{\omega_{t}-\omega_{e}}{\omega_{e}}\right| \cdot 100 \%$ & 11.45 & 0.36 & 0.80 & 0.19 & 0.32 \\
\hline
\end{tabular}


Comparing the experimental and calculated free vibration frequencies, one can notice compatibility within the values, and it allows one to state that the theoretical model representing the real object appropriately. The biggest relative error occurs for the first vibration frequency, but it may be due to the following factors: giving consideration in the mathematical model to the infinity rigidity of fixed system and influence of experimental stand on the tested beam.

\section{Conclusions}

In this paper, the free vibration problem of the cantilever tapered Timoshenko beam has been formulated and solved on the basis of Lagrange multiplier formalism.

On the basis of a comparison between numerical calculations and experimental results, the reliability and accuracy of the present mathematical method have been proved. However, if the results have to be received with the demanded precision, the number of segments approximating the tapered beam and terms of coefficients $C_{n_{k, r}}$ should be appropriately determined.

\section{Acknowledgments}

The study has been carried out within statutory research BS/PB-1-1013026/11/P of the Institute of Mechanics and Machine Design Foundations of Czestochowa University of Technology.

\section{References}

[1] Firouz-Abadi R.D., Haddadpour H., Novinzadeh A.B., An asymptotic solution to transverse free vibrations of variable-section beams, Journal of Sound and Vibration 2007, 304, 530-540.

[2] Hsu J.H., Lai H.Y., Chen C.K., Free vibration of non-uniform Euler-Bernoulli beams with general elastically end constraints using Adomian modified decomposition method, Journal of Sound and Vibration 2008, 318, 965-981.

[3] Yagci B., Filiz S., Romero L.L., Ozdoganlar O.B., A spectral-Tchebychev technique for solving linear and nonlinear beam equations, Journal of Sound and Vibration 2009, 321, 375-404.

[4] Cleghorn W.L., Tabarrok B., Finite element formulation of a tapered Timoshenko beam for free lateral vibration analysis, Journal of Sound and Vibration 1992, 152, 461-470.

[5] Eisenberger M., Dynamic stiffness matrix for variable cross-section Timoshenko beams, Communications in Numerical Methods in Engineering 1995, 11, 507-513.

[6] Tong X., Tabarrok B., Vibration analysis of Timoshenko beams with non-homogeneity and varying cross-section, Journal of Sound and Vibrations 1995, 186(5), 821-835.

[7] Liao M., Zhong H., Nonlinear vibration analysis of tapered Timoshenko beams, Chaos, Solitons and Fractals 2008, 36, 1267-1272.

[8] Attarnejad R., Semnani S.J., Shahba A., Basic displacement functions for free vibration analysis of non-prismatic Timoshenko beams, Finite Elements is Analysis and Design 2010, 46, 916-929 . 
[9] Timoshenko S.P., On the correction for shear of the differential equation for transverse vibrations of prismatic bars, Philosophical Magazine 1921, 6(41), 744-746.

[10] Timoshenko S.P., On the transverse vibrations of bars of uniform cross section, Philosophical Magazine 1922, 6(43), 379-384.

[11] Posiadała B., Free vibrations of uniform Timoshenko beams with attachments, Journal of Sound and Vibrations 1997, 204(2), 359-369.

[12] Posiadała B., Modelling and analysis of continuous-discrete mechanical systems, Application of the Lagrange multiplier formalism, Seria Monografie nr 136, Wydawnictwo Politechniki Częstochowskiej, Częstochowa 2007 (in Polish).

[13] Cekus D., Use of Lagrange multiplier formalism to solve of transverse vibrations problem of stepped beams according to Timoshenko theory, Scientific Research of the Institute of Mathematics and Computer Science 2011, 2(10), 49-56.

[14] Cowper G.R., The shear coefficient in Timoshenko's beam theory, Journal of Applied Mechanics 1966, 33(2), 335-340. 
